degree the original spiral form of the birth tufts, the adult fleece consisting of long, separate curls or ringlets; others, such as the Cheviot, may lose all the spiral or wavy regularity and take on a loosely matted, frizzy character, as in the Negro.

Fine Merino wool shows the extreme of regularity in crimp formation; the number has been found to vary inversely with the thickness of the fibre and to be a periodic function of time. Among wool problems, probably not one has been more fully discussed than that of the production of crimps, but it is manifest from the above that they are of the same nature as the loops in Negro fibres, and are therefore to be interpreted as a periodic series of twists and reversals impressed on a spiral foundation. Hence the change from the spiral tufts of the birth coat to the crimped definitive coat of the adult, with suppression of the spiral form, is to be associated with the axial twisting of the fibres. The spiral is transformed by a regular succession of mechanical twists and reversals into a periodic series of crimps, which give to wool much of its textile value.

By means of the fibre rotator Rossouw ${ }^{2}$ has shown that in each complete wave or crimp there are two twists and two reversals of $180^{\circ}$, the minor axis always showing at the crest and the trough of the wave and the major axis along each side.

The constructive factors involved in the production of the spiral growth of the fibre and its frequent reversals, as well as the regular or irregular incidence of the axial twist, are not yet fully understood. S. G. Barker ${ }^{3}$ has shown that they may be interpreted as resulting from two simple harmonic forces acting at right angles, but the biological nature of these forces is not yet clear. That the crimps are to be associated with the primarily spiral, axially twisted condition of the fibres, clarifies the problem. A complete crimp is seen to represent an axial twist of $360^{\circ}$, and in the plane of the microscope exhibits two minor and two major axes. Both vary in number inversely with the thickness of the fibre and are a periodic function of time.

* Dr. S. G. Barker has further obtained from Dr. O. L. Mohr, Oslo, samples of the hair occurring in the Norwegian family recently mentioned in NATURE, 133, 695, May 13, 1933. Under his direction these have been fully stndied hy Miss A. L. Walker, by means of the fibre rotator, and the measurements expressed in graphic form. Apart from their reduced pigmentation, thev are found to conform in every way with hair from the typical ulotrichous races.

1 Nature, 131, Feb. 11, 1933.

2 J. Text. Inst., 22, July 1931.

${ }^{3}$ Trans. Farad. Soc., 29, January 1933.

\title{
Cultural History in Middle America*
}

A NEW series of publications, appearing under the title Ibero-Americana, is to be issued by the University of California, which will form a complement to the "Publications in American Archæology and Ethnology" already published by that body. It will consist of studies in Latin-American cultures, native and transplanted, pre-European, colonial and modern. Physical and racial backgrounds are to have a place in the series, but it is anticipated that the studies, in the main, will be contributions to culture history. There will be no regular date for publication, and each issue will be independent and individually paged, its price varying according to size. The editors are Dr. Herbert E. Bolton, Prof. A. L. Kroeber and Dr. C. O. Sauer.

The scope and character of the series may be gauged from the first three numbers which have been published. Broader in scope than the archæological series of publications, this series, if continued on present lines, promises to be of considerable interest to students of American culture.

In "Aztatlán", Dr. Carl Sauer and Mr. Donald Brand describe a previoúsly unrecorded culture in Sinaloa and Nayarit. The culture area is situated in a shallow strip of country on the Pacific coast of Mexico, which stretches from the valley of the Rio Grande de Santiago at the south to Culiacán in the north. This is the Terra Caliente of Guzman's Nueva Galicia, for which the oldest regional term is Aztatlán. In this area, more than thirty mounds were visited, probably only a small fraction of the total number which exists. All are situated either on flood plains or on their margins, the inconveniences of the situation being indicated by the number of artificial mounds on which the habitations once stood. Most of those in the Culiacán valley do not exceed three to four feet in height; but the

*Ibero-Americana. 1: Aztatlán, Prehistoric Mexican Frontier on the Pacific Coast. By Carl Sauer and Donald Brand. Pp. 92 (14 plates). 2 dollars. 2 : The Comparative Ethnology of Norther Mexico before 1750. By Ralph L. Beals. Pp. vi +93-226. 1.35 dollars. 3: The Road to Cíbola. By Carl Sauer. Pp. iv +58 . 75 cents. (Berkeley, Calif.: University of California Press, 1932.) largest in the Presidio valley is some thirty feet high.

The general character of the culture is purely southern. The district would appear to have acquired its culture well back in the Toltecan period and is pre-Aztecan in character. Culiacán forms a frontier facing north. The whole area is a long north-western tongue of prehistoric Mexican culture. It does not rate high in stone carving; but the stone implements have distinctive qualities. The culture is excellent in pottery making, the ware being thin, tough, of fine paste and highly polished. It has a basic colour decoration in parallel banding but with engraving as its most characteristic feature. This is applied equally to monochrome and polychrome.

The population would appear to have been almost completely destroyed in the early Spanish occupation by Guzman in 1530 .

The discovery of the Aztatlán culture was made while the authors were seeking evidence for the existence of a prehistoric corridor between the Mexican highland and the Pueblo country of the south-western States, a problem upon which both the second and the third studies in this series also have a direct bearing. No. 3 "The Road to Cíbola", which here may be dismissed in a few words, traces the course followed by the early Spanish conquerors towards the north-west in their search for a legendary city of fabulous wealth. The interest of the study lies in the fact that their way lay along the main trails beaten by many generations of Indian travel which later became the historic highways, forging a link between the prehistoric past and the modern present.

The third study, "The Comparative Ethnology of Northern Mexico before 1750", bears even more directly on the problem of the relation of the SouthWestern Pueblos to Middle and South America. Dr. Ralph L. Beals has extracted from early Spanish sources the evidence relating to the culture of the area of northern Mexico which lies between the United States frontier and a line drawn from the mouth of the Rio Panuco to the southern boundary 
of Jalisco. This is an area of transition, of which very little is known to the anthropologist.

Dr. Beals has collected a mass of information on elements of culture which can be attributed definitely to tribal units or groups. From this evidence certain tentative inferences are drawn as to the cultural provinces of northern Mexico and an attempt is made to trace the influence of Middle America on the culture of the south-west and south-east of North America.

In the discussion of cultural provinces a large nonagricultural area in northern Mexico with a lack of pottery is defined. Further, it is shown that, at the time of the conquest, sub-Mexican cultures existed in Sinaloa (see above), while a culture of sub-Mexican or sub-Mayan type, utilising truncated stone-faced pyramids and stone or adobe architecture, was to be found about 200 miles from the Rio Grande in Tamaulipas. Continuous distributions for certain traits between Mexican cultures and the southwestern States are established, including stone and adobe architecture, the use of turquoise, idols, pottery and architecture. It was also discovered that there are a number of traits of similar distribution in the south-eastern States, northern Mexico and Middle America, such as the religious complex of altars, priests, perpetual fires, temples, temple mounds, and ceremonial trees, which suggests a definite connexion of the south-east with the region of higher culture in the south.

While recognising the influence of one area on another, it must also not be overlooked that very real development was made locally; for example, cultivation, after introduction from the south, was adapted to the local environment and dry-farming methods were developed.

\section{New Science Laboratories in Aligarh}

ATHOUGH Aligarh has been a centre of learn$A$ ing in India during the last sixty years, a new era has started with the erection of the new science laboratories for the Aligarh Muslim University. The laboratories are the fruits of the labours of Nawab Masood Jung Dr. S. R. Massod, the Vice-Chancellor of the University.

The laboratories for physics, chemistry, botany and zoology occupy separate blocks, each fitted with up-to-date appliances for research and advanced studies. To each of these laboratories is attached a library, having all the necessary and important scientific books and periodicals in English and other European languages.

Physical Laboratory: The Department of Physics is installed in a building consisting of about sixty rooms, in two blocks--one for teaching and the other for research and advanced studies. Prof. R. Samuel is the Nizam professor of physics and chairman of the Department; Dr. R. K. Asundi is reader in physics. The Department has been equipped with the following apparatus: Zeiss photometer, Zeiss three-prism glass spectrograph, Zeiss two-prism quartz spectrograph, two vacuum spectrographs, soft X-ray spectrograph, Zeiss comparator, Zeiss grating spectrograph, gratings, quartz spectrographs, quartz and glass monochromators, apparatus for electronic interference, etc.

At present there are some eighteen students working in the Laboratory on problems ranging from the study of absorption and emission spectra in the extreme ultra-violet, ultra-violet, visible and the infra-red region to problems of electronic interference, elećtronic diffraction, soft X-rays, photochemical problems, etc.

Chemical Laboratory: Prof. R. F. Hunter is Nizam professor of chemistry and chairman of the Depart. ment of Chemistry; Dr. R. D. Desai and Lt. M. Haider Khan are readers in chemistry.

Research work on the unsaturation and tauto. meric mobility of heterocyclic compounds, the electronic structure of organic perhalides and perhalide ions, and the lability of unshared electrons in organic compounds of different elements, is in progress. Arrangements have been made for the study of absorption spectra and dipole moments and polarisation of organic compounds as well.

Botanical Laboratory: The Department of Botany is under Dr. R. A. Khan, who has recently returned from Cambridge.

Special arrangements have been made for the study of problems in plant physiology. Facilities are given for research in every branch of botany and a botanical garden is attached to the Department. A museum containing tropical plants is attached to the Department.

Zoological Laboratory: Dr. M. B. Mirza, reader in zoology, is the chairman of the Department of Zoology.

A special feature of the Department is the museum attached to it. The museum contains all the necessary specimens for teaching work, and also a large number of rare specimens.

\section{University and Educational Intelligence}

BristoL.-Dr. H. Jones has been appointed lecturer in theoretical physies.

DubLrn.- On July 6, the following honorary degrees were conferred, among others : Sc.D. on Prof. W. L. Bragg, Langworthy professor of physics in the University of Manchester, and Prof. J. S. Haldane, honorary professor of mining and director of the Mining Research Laboratory in the University of Birmingham; Litt.D. on Sir Percy Nunn, professor of education in the University of London, and Dr. Douglas Hyde, well known for his work in connexion with Irish university education and folk-lore.

EDINBURgh.--At the graduation ceremony on June 30 , the honorary degree of doctor of laws was conferred on the Right Hon. Craigie Aitchison, M.P., Lord Advocate; Sir James Caw, formerly director of the National Galleries of Scotland; Sir Henry Dale; Prof. G. H. Hardy; Sir Alexander Houston; The Right Hon. Baron Meston, Chancellor of the University of Aberdeen; Sir Hugh Arthur Rose; Dr. J. C. Smith, formerly senior chief inspector of schools in Scotland; Dr. W. W. Tarn.

The degree of D.Litt. was conferred on Mr. G. G. Neill Wright for a thesis entitled "The Psychological Analysis of Social Structure"; and the degree of D.Sc. on Mr. J. A. Fraser Roberts for a thesis entitled "Studies on the Biology of the Sheep"; on Dr. B. P. Wiesner for a thesis entitled "Maternal Behaviour in the Rat"; and on Mr. G. B. Brook for a thesis entitled "Experimental and Clinical Studies of the Spine of the Dog".

Glasgow.-By her will, Miss B. A. Gray has bequeathed a sum of $£ 8,000$ to the University to endow a "Matthew Gray Scholarship", as a travelling scholarship for students of engineering. 